\title{
Effect of Partial Heating on Natural Convective Heat Transfer in an Inclined Porous Cavity
}

\author{
Dr. Amir S. Dawood \\ Assistant Professor \\ Muyassar E. Ismaeel \\ Assistant Lecturer \\ Department of Mechanical Engineering, Mosul University
}

\begin{abstract}
This paper reports a numerical study of natural convection heat transfer in an inclined square porous enclosure partially heated from bottom. The finite difference technique with Gauss - Siedel method is used to solve the governing equations. The governing parameters are modified Rayleigh number, inclination angle, and insulation ratio (Length of insulated part / Total length of the cavity). It is seen that the governing parameters have pronouns effect on the rate of heat transfer. However, the increases in inclination angle increase the rate of heat transfer until it becomes maximum then decrease to unity at the angle $180^{\circ}$. Also, the increase of insulation ratio decreases the rate of heat transfer and the angle of maximum heat transfer.
\end{abstract}

Keywords : Natural Convection, Porous, Partial Heating, Inclined.

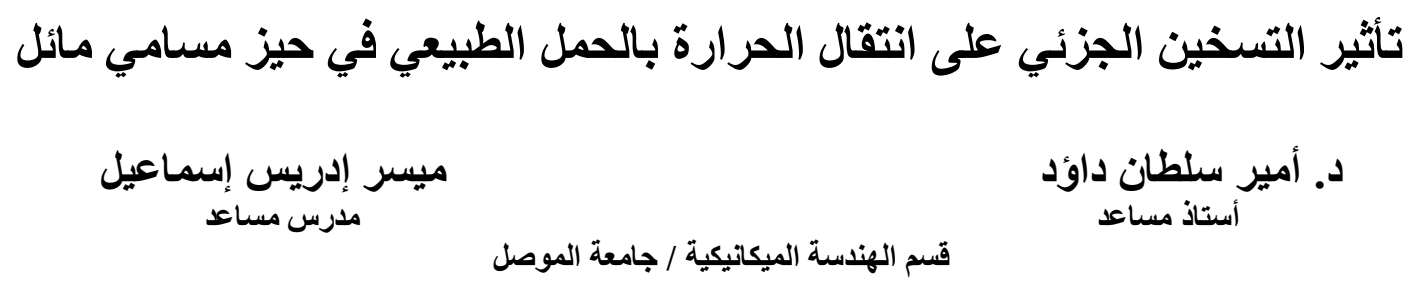

الخلاصة

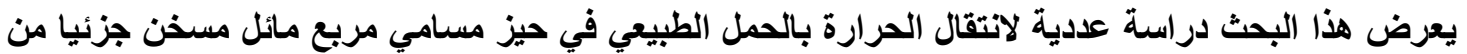

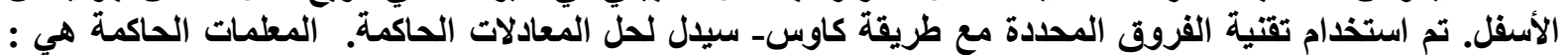

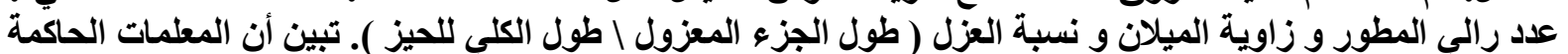

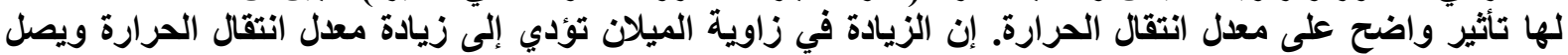

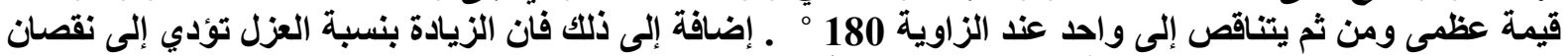

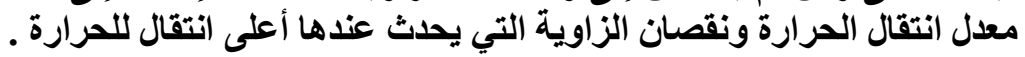




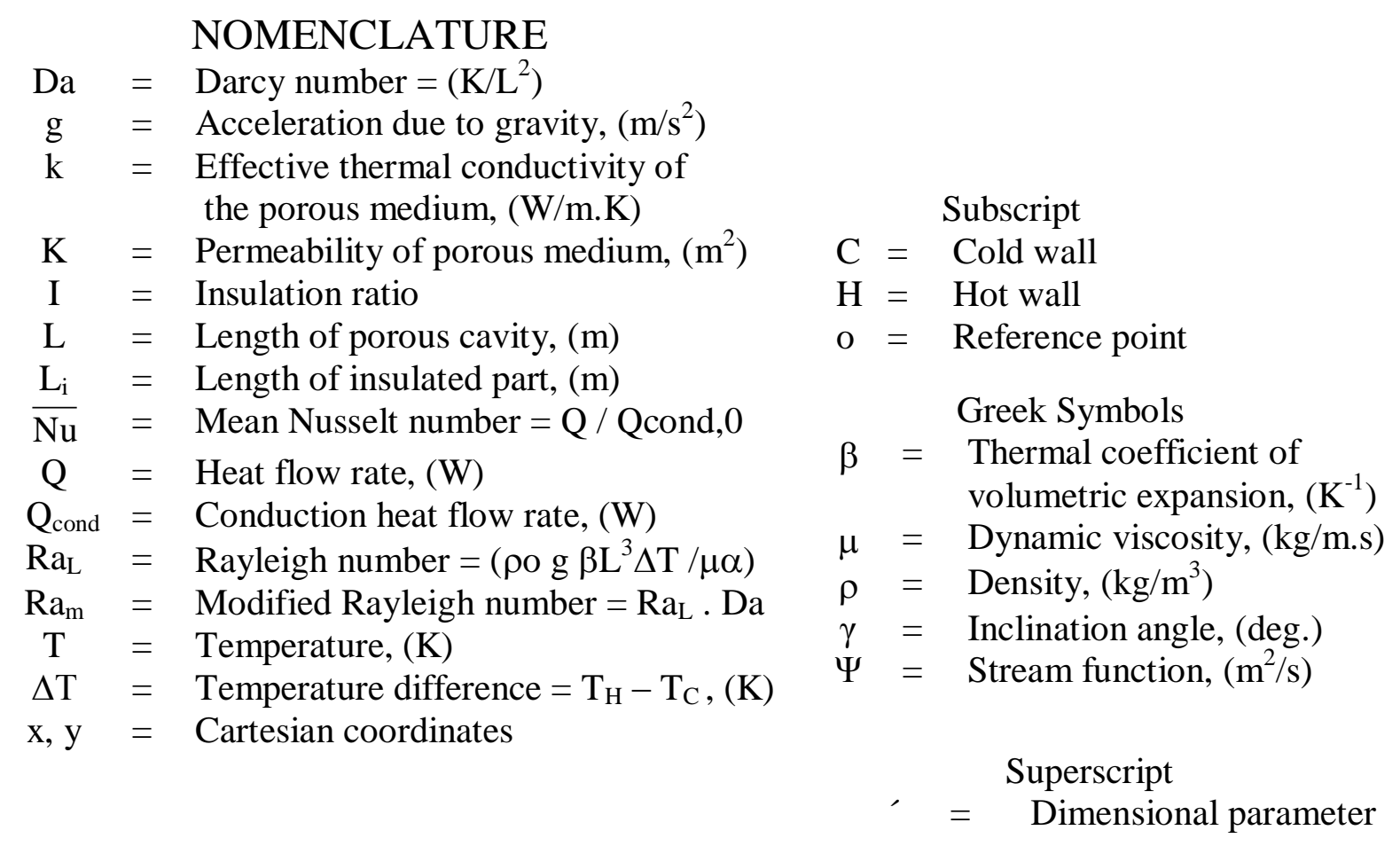

\section{Introduction}

Thermally driven flows in porous media have received a great deal of attention because of the increasing interest in engineering application such as geothermal energy systems, compact heat exchangers, nuclear engineering, cooling of radioactive waste containers etc.. [1].

Natural convection heat transfer in a rectangular or square enclosure filled with a fluid saturated porous medium under different temperature or heat flux boundary condition has been extensively analyzed in earlier studies. The case of partial heating was one of the categories in these studies. Lai and Kulacki [2] in 1991 studied experimentally free and mixed convection in horizontal porous layer locally heated from below. They represented their data through empirical correlations for different ratios of the length of the heat source to the layer height. Dawood [3] in 1996 reported numerical results for natural convection in a rectangular enclosure filled with porous medium with partial heating from below. He studied two different boundary conditions of cooling to the left and upper sides separately and different aspect ratios. His numerical results show that the relative increase in heat fluxes take place at an aspect ratio of unity. Bourich et. al. [4] in 2004 reported numerical results of twodimensional double-diffusive natural convection in a square porous cavity partially heated from below while its upper surface is cooled at a constant temperature. The vertical walls of the porous matrix are subjected to a horizontal concentration gradient. They analyzed the effect of the governing parameters on fluid characteristics. Pakdee and Rattanadech [5] in 2006 studied numerically transient natural convection flow through porous medium in a rectangular cavity with convection surface conditions. The cavity is insulted except the top wall that is partially exposed to an outside ambient. It was found that the heat transfer coefficient, Rayleigh number and Darcy number the considerably influenced characteristics of flow and heat transfer mechanisms. Oztop [1] in 2007 investigated numerically natural convection heat transfer in a partially cooled surface, which located in the bottom wall, and inclined rectangular enclosure filled with saturated porous media. He studied the effect of 
Rayleigh number, length of cooler, location of cooler, inclination angle and aspect ratio. He found that inclination is the dominant parameter on heat transfer and fluid flow as well as aspect ratio.

\section{Physical Modeling}

The physical model is a square cavity filled with fluid saturated porous media. The problem under study with the coordinate system and boundary conditions are shown in Figure ( 1 ). The length of insulated part of the bottom wall is $\left(\mathrm{L}_{\mathrm{i}}\right)$ while the remainder is isothermal part at temperature $\left(\mathrm{T}_{\mathrm{H}}\right)$. The Top wall at a lower isothermal temperature $\left(\mathrm{T}_{\mathrm{C}}\right)$ and the side walls are insulated. Gravity acts negative at y-direction

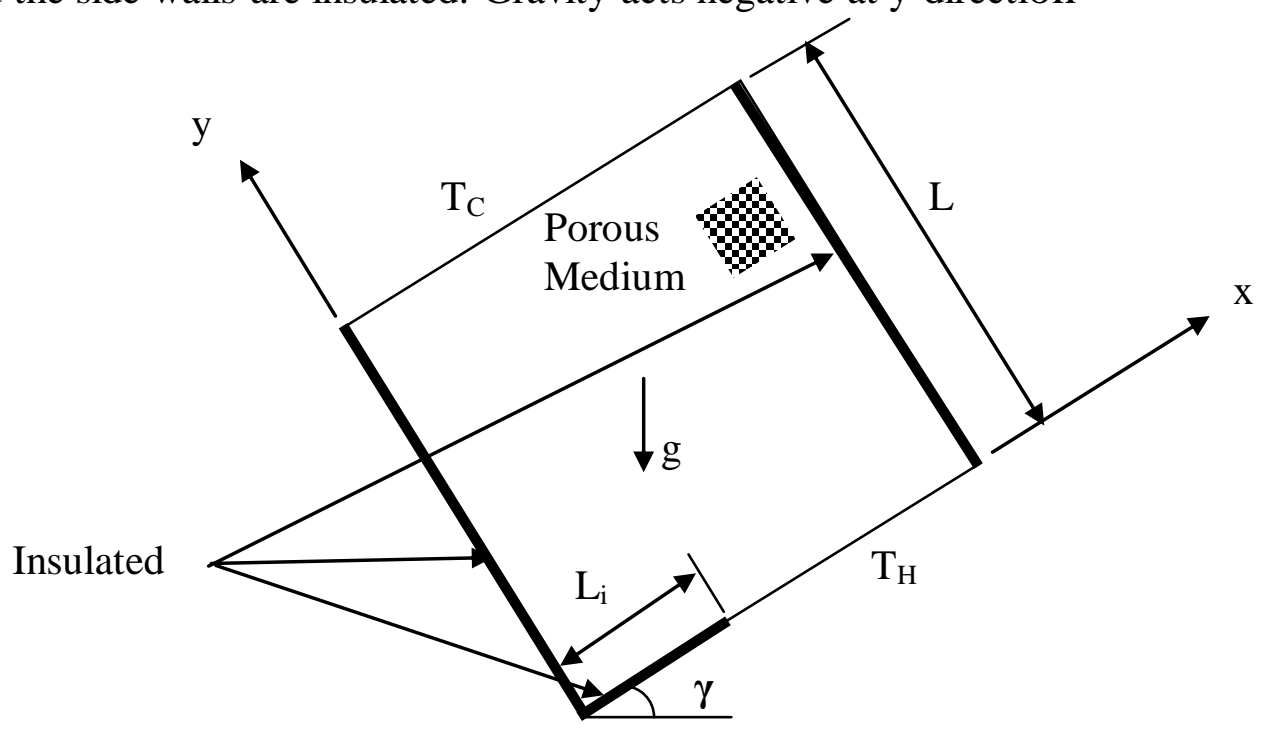

Figure ( 1 ) Physical model.

\section{Equations}

In this investigation, the porous matrix is assumed rigid and isotropic in thermal conductivity. Additionally, it has been assumed that the porosity and permeability of the homogeneous porous medium are uniform. On the other hand, the fluid is assumed as Newtonian, incompressible and the flow is laminar. Also, the fluid and solid properties are constant except for the density of fluid change with temperature, which is Boussinesq approximation is applied. Finally, it is assumed that the fluid and porous medium are in thermal equilibrium and the fluid motion is described by Darcy's law.

For two-dimension and steady state condition, the non-dimensional form of the governing equations in terms of the stream function $\Psi$ and temperature $T$ are [6] :

$$
\begin{aligned}
& \frac{\partial^{2} \Psi}{\partial \mathrm{x}^{2}}+\frac{\partial^{2} \Psi}{\partial \mathrm{y}^{2}}=-\mathrm{Ra}_{\mathrm{m}}\left[\frac{\partial \mathrm{T}}{\partial \mathrm{x}} \cos \gamma-\frac{\partial \mathrm{T}}{\partial \mathrm{y}} \sin \gamma\right] \\
& \frac{\partial \Psi}{\partial \mathrm{y}} \frac{\partial \mathrm{T}}{\partial \mathrm{x}}-\frac{\partial \Psi}{\partial \mathrm{x}} \frac{\partial \mathrm{T}}{\partial \mathrm{y}}=\frac{\partial^{2} \mathrm{~T}}{\partial \mathrm{x}^{2}}+\frac{\partial^{2} \mathrm{~T}}{\partial \mathrm{y}^{2}}
\end{aligned}
$$


Where the non-dimensional variables are defined as :

$\mathrm{x}=\frac{\mathrm{x}^{\prime}}{\mathrm{L}} \quad, \quad \mathrm{y}=\frac{\mathrm{y}^{\prime}}{\mathrm{L}} \quad, \quad \Psi=\frac{\Psi^{\prime} \mathrm{H}}{\mathrm{kL}} \quad$ and $\quad \mathrm{T}=\frac{\mathrm{T}^{\prime}-\mathrm{T}_{\mathrm{C}}^{\prime}}{\mathrm{T}_{\mathrm{H}}^{\prime}-\mathrm{T}_{\mathrm{C}}^{\prime}}$

For more details, the variables are listed in nomenclature. The governing parameters are

$$
\mathrm{Ra}_{\mathrm{m}}=\frac{\mathrm{Kg} \beta\left(\mathrm{T}_{\mathrm{H}}^{\prime}-\mathrm{T}_{\mathrm{c}}^{\prime}\right) \mathrm{L} \rho_{\mathrm{o}}}{\mathrm{k} \mu}, \quad \mathrm{I}=\frac{\mathrm{L}_{\mathrm{i}}}{\mathrm{L}}, \quad \gamma
$$

the modified Rayleigh number $\mathrm{Ra}_{\mathrm{m}}$, the insulation ratio and the inclination angle respectively.

The non-dimensional boundary conditions are :

$$
\begin{array}{ll}
\Psi=0 & \text { on all walls } \\
\frac{\partial \mathrm{T}}{\partial \mathrm{y}}=0 & \text { for } \mathrm{y}=0 \text { and } 0 \leq \mathrm{x} \leq \mathrm{I} \\
\mathrm{T}=1 & \text { for } \mathrm{y}=0 \text { and } \mathrm{I} \leq \mathrm{x} \leq 1 \\
\mathrm{~T}=0 & \text { for } \mathrm{y}=1 \text { and } 0 \leq \mathrm{x} \leq 1 \\
\frac{\partial T}{\partial x}=0 & \text { for } \mathrm{x}=0,1 \text { and } 0 \leq \mathrm{y} \leq 1
\end{array}
$$

The average Nusselt number defined as :

$$
\overline{\mathrm{Nu}}=\int_{0}^{1} \frac{\partial \mathrm{T}}{\partial \mathrm{y}} \mathrm{dx}
$$

\section{Numerical Solution}

The finite difference technique is applied to solve the governing ( equations (1) and (2) ) with the boundary conditions ( equation (5) ). The Gauss - Siedel iterative method with an accuracy of $\sum\left|\mathrm{TN}_{\mathrm{ij}}-\mathrm{T}_{\mathrm{ij}}\right| \leq 10^{-4}$ is used. Due to the difference in the areas of the hot and cold walls, it was difficult to calculate a consistent value for the heat flux between those walls. Thus, a procedure mentioned in reference [3] is followed to compute the heat flux. The validity of the present work is checked with the classical natural convection heat transfer problem in differentially heated square porous enclosure from sides. Table (1) shows the comparison of the mean Nusselt number obtained in the present work and those of others. It is clear that the obtained values are in good agreement with the tabulated values.

Table (1) Comparison between present code results of Nusselt number with previous works.

\begin{tabular}{|c|c|c|c|c|c|c|}
\hline study & \multicolumn{6}{|c|}{ Mean Nusselt Number } \\
\cline { 2 - 7 } $\mathrm{Ra}_{\mathrm{m}}$ & Hakan [1] & Baytas [6] & Saied et. al. [9] & Hakan et. al. [8] & Bejan [10 ] & $\begin{array}{c}\text { Present } \\
\text { Work }\end{array}$ \\
\hline 100 & 2.980 & 3.160 & 3.002 & ------- & ------ & 3.243 \\
\hline 1000 & ------ & ------ & ------ & 13.564 & 15.80 & 14.45 \\
\hline
\end{tabular}




\section{Results and discussion}

This investigation was performed to study the steady state, laminar natural convection heat transfer in an inclined square porous cavity with the parameters as modified Rayleigh number $(0-500)$, inclination angle $\left(0^{\circ}-180^{\circ}\right)$ and insulation ratio $(1 / 4,1 / 3$, $1 / 2$ and $2 / 3$ ).

To show the effect of Rayleigh number $\left(\mathrm{Ra}_{\mathrm{m}}\right.$ ) on flow field and heat transfer, the other parameters have been fixed, so, the discussion is presented for insulation ratio of ( $\mathrm{I}=$ $1 / 2)$ and inclination angle of $\left(\gamma=10^{\circ}\right)$.

Figure ( 2$)$ represents the streamlines and isotherms for different values of Rayleigh number. The situation of $\mathrm{Ra}_{\mathrm{m}}=0$, represents a pure conduction mode of heat transfer from hot wall to cold wall. In this case, the isothermal lines are parallel to the isothermal walls and there is no circulation of the field. The increases in Rayleigh number led to set up the convection mode of heat transfer because the buoyancy force overcome the viscous force, this is clear in Figure ( $2-\mathrm{a}, \mathrm{b}$ and $\mathrm{c}$ ). Thus, for $\mathrm{Ra}_{\mathrm{m}}=$ 10 as depicted in Figure( 2-a ), a weak streamlines appear and similar isotherms to that at $\mathrm{Ra}_{\mathrm{m}}=$ 0 because the conduction still is the dominant mode of heat transfer. Continuous increasing in Rayleigh number enhances the convection mode which is clear from the values of streamlines and the gradient of isothermal lines as presented in Figure ( 2- b and $\mathrm{c}$ ).
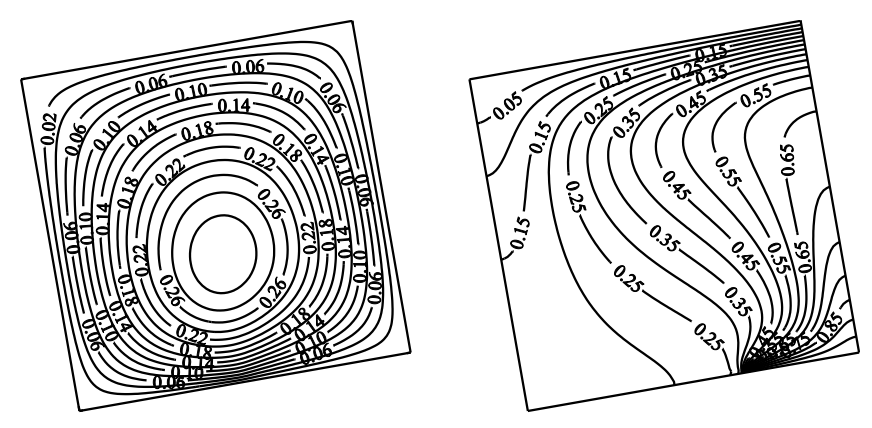

( a )

(n)

(a)

( $b$ )
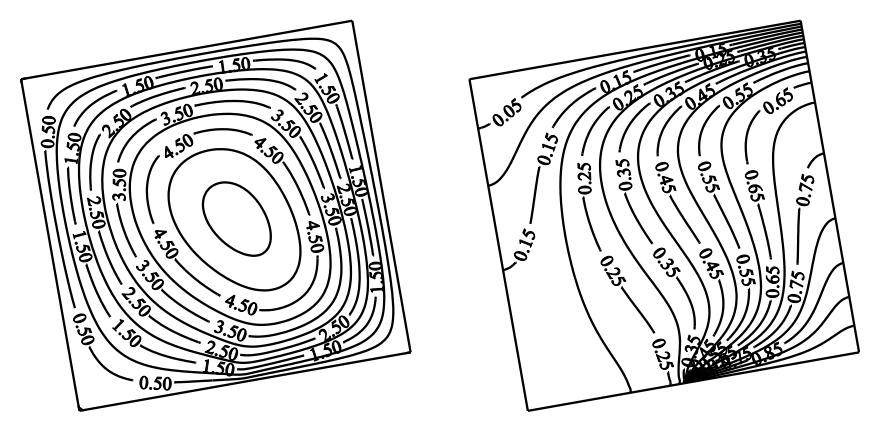

Figure ( 2 ) The streamlines and isotherms at insulation ratio of $(1 / 2)$ and inclination angle of ( 10 ) for different values of Rayleigh number : ( a ) 10 , (b ) 100 and (c ) 400 . 
Results of the average Nusselt number $(\overline{\mathrm{Nu}})$ are presented in Figure ( 3 ). Figure ( 3-a ) shows the effect of Rayleigh number on the Nusselt number with different values of inclination angle and insulation ratio $(\mathrm{I}=1 / 4)$. It shows that $(\overline{\mathrm{Nu}})$ increases as $\left(\mathrm{Ra}_{\mathrm{m}}\right)$ increases.

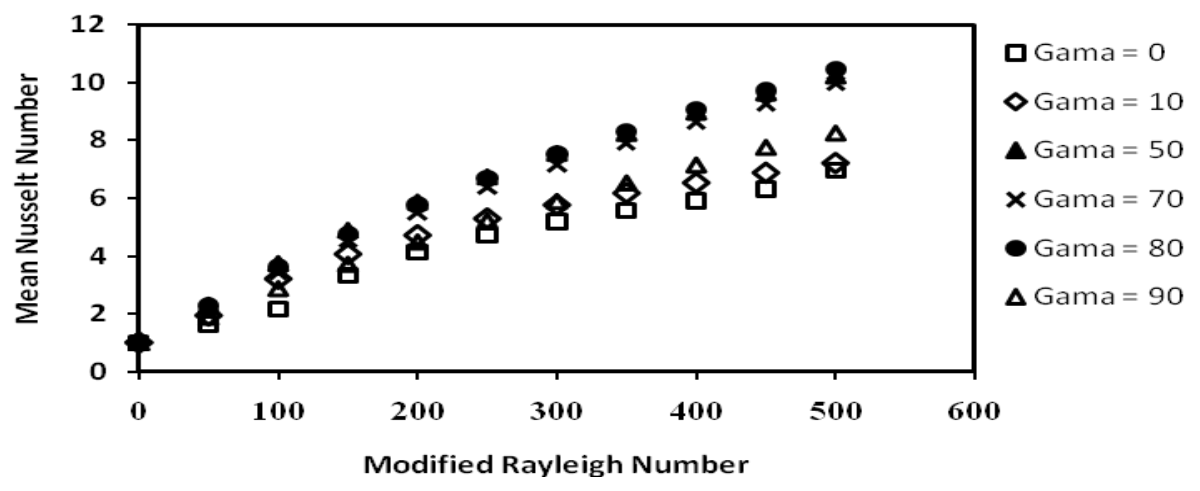

(a)

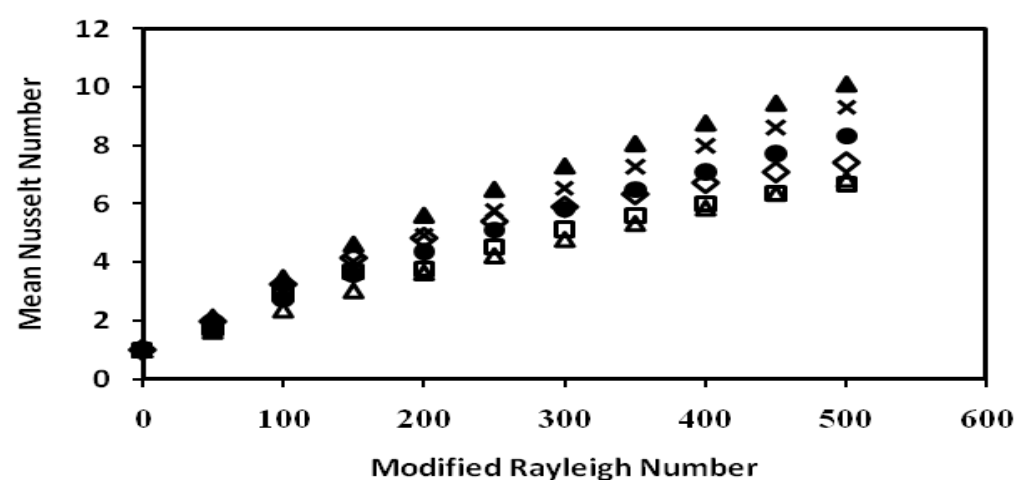

(b)

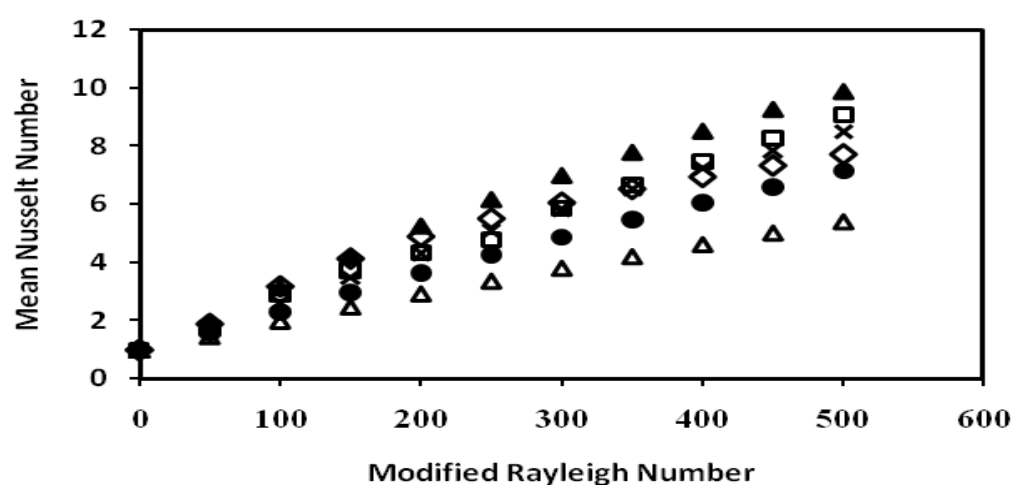

(c)

Figure ( 3 ) Effect of modified Rayleigh number on the Nusselt number with different values of inclination angles and insulation ratio as :

$$
\text { ( a ) } \mathrm{I}=1 / 4, \text {, b ) } \mathrm{I}=1 / 2 \text { and ( c ) } \mathrm{I}=2 / 3 \text {. }
$$

The orientation of the cavity has been changed from $0^{\circ}$ ( heated from below ), passing $90^{\circ}$ (heated from side) and stopping at $180^{\circ}$ (heated from top). The effect of inclination angle on temperature distribution and flow field is shown in Figure ( 4 ) for insulation ratio ( $\mathrm{I}=2 / 3)$ and Rayleigh number $\left(\mathrm{Ra}_{\mathrm{m}}=150\right)$. 
It is clear that as inclination angle increases from $0^{\circ}$ to $60^{\circ}$ the convection mode of heat transfer becomes more dominant. Further increase in inclination reduces the convection mode and the conduction mode be the dominant. At inclination angle $180^{\circ}$, as shown in Figure ( $4-e$ ), the heat is transferred by pure conduction.

( a )
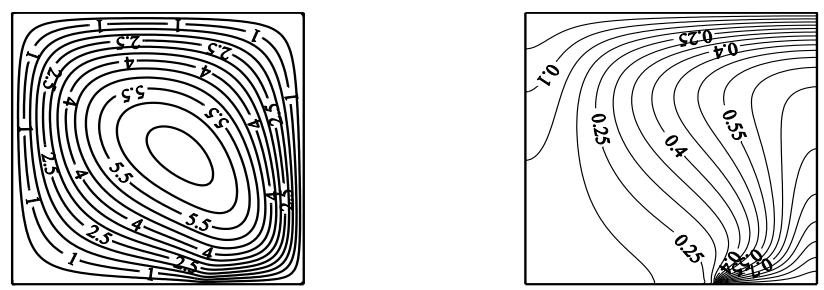

( $\mathrm{b})$
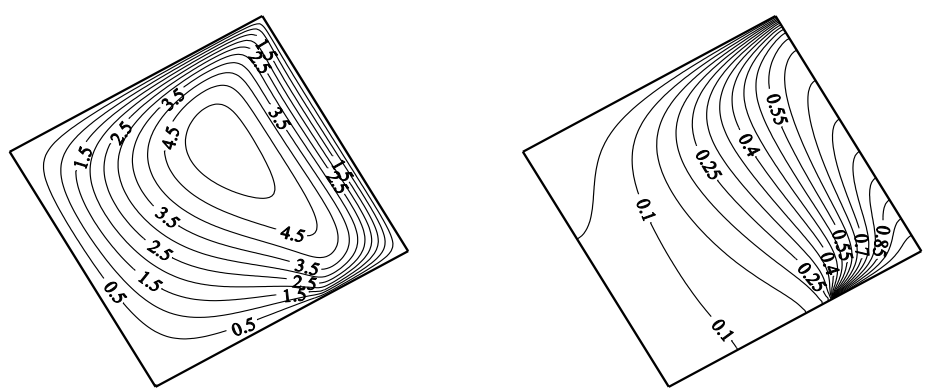

( c )
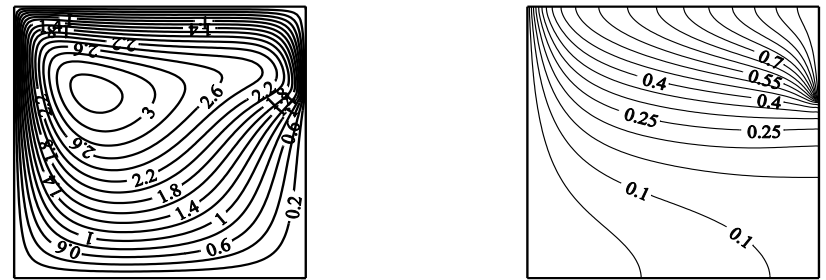

$(\mathrm{d})$
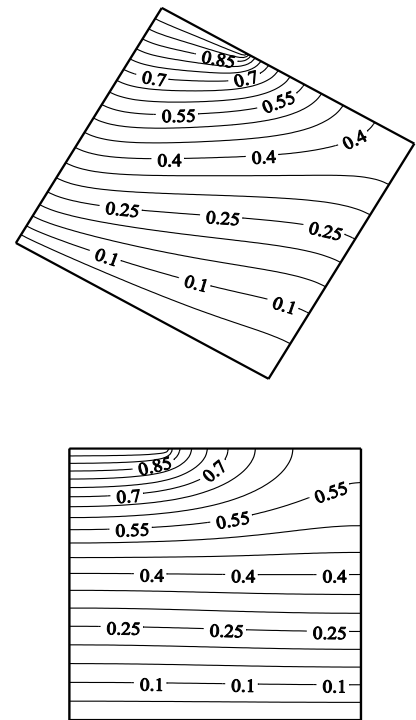

Figure ( 4 ) Effect of inclination angle on flow field and temperature distribution for insulation ratio $(2 / 3)$ and Rayleigh number $(150)$. The inclination angle is : ( a ) $0^{\circ}$, ( b ) $60^{\circ}$, (c ) $90^{\circ}$, ( d ) $150^{\circ}$ and ( e ) $180^{\circ}$. 
Figure ( 5 ) represents the relationship between Nusselt number $(\overline{\mathrm{Nu}})$ and inclination angle $(\gamma)$ at various insulation ratio. As shown in Figure ( 5-a ), Nusselt number increases as inclination angle increase until be maximum then it reduces to be unity at $180^{\circ}$. The angle of maximum ( $\overline{\mathrm{Nu}}$ ) changes with changing Rayleigh number, for example it occurs at $\gamma=50^{\circ}$ for $\mathrm{Ra}_{\mathrm{m}}=200$ while it occurs at $\gamma=57^{\circ}$ for $\mathrm{Ra}_{\mathrm{m}}=500$.

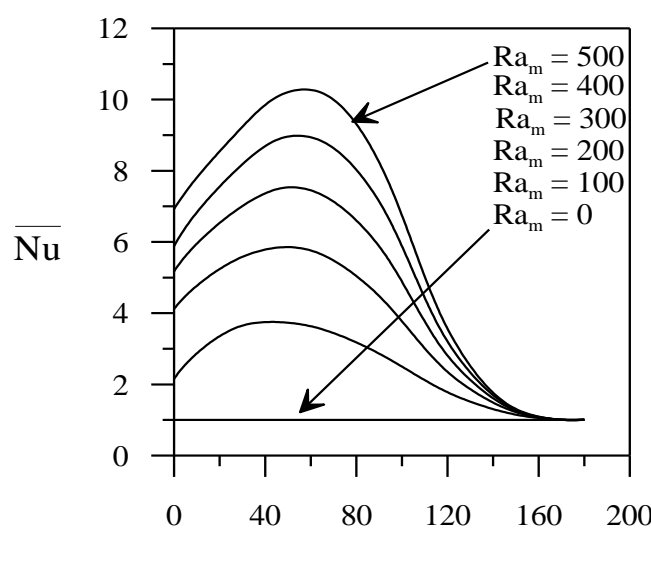

Inclination Angle ( Degree )

( a )

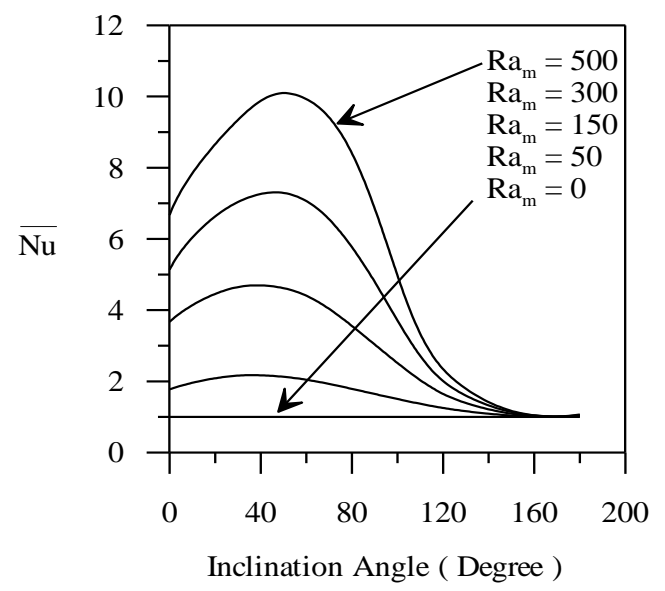

(c)

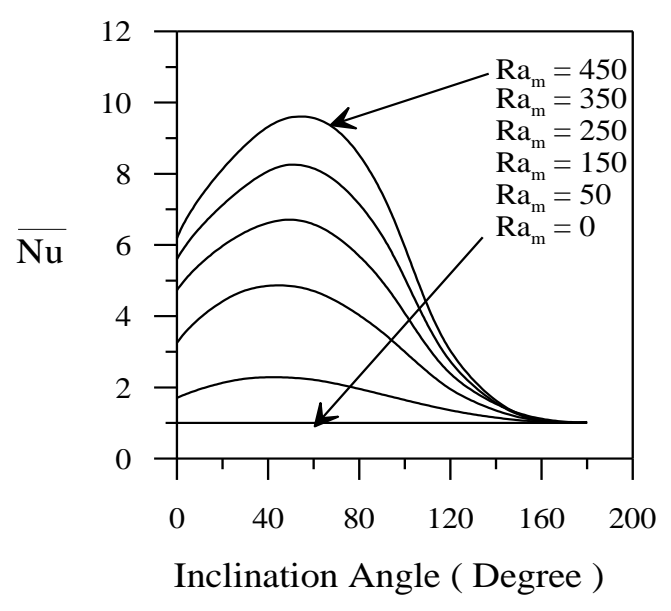

( b )

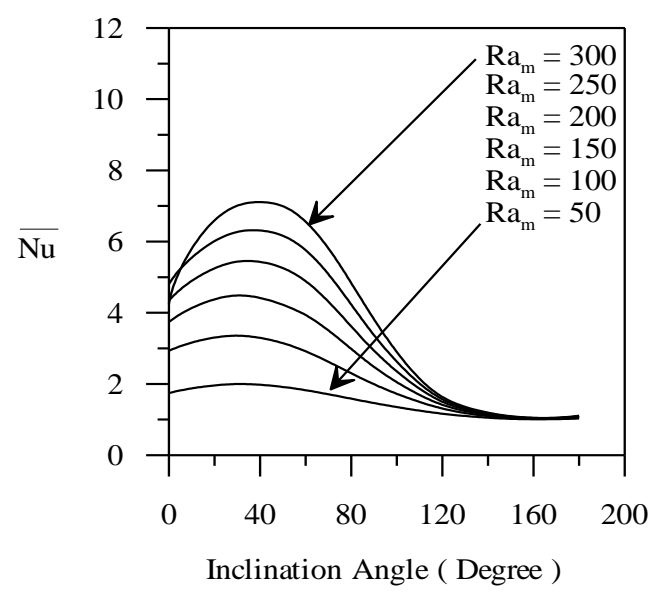

(d)

Figure ( 5 ) Effect of inclination angle on Nusselt number with different values of Rayleigh number and insulation ratio as :

(a ) $\mathrm{I}=1 / 4$, , b ) $\mathrm{I}=1 / 3$, (c) $\mathrm{I}=1 / 2$ and ( d ) $\mathrm{I}=2 / 3$.

The effect of insulation ratio ( I ) on flow field and temperature distribution at Rayleigh number $\left(\mathrm{Ra}_{\mathrm{m}}=250\right)$ is shown in Figures $(6)$ and $(7)$ for inclination angle $0^{\circ}$ and $30^{\circ}$ respectively. Figure ( 6 -a ) shows the situation of insulation ratio equal to ( $\left.I=1 / 4\right)$. In this case, the flow is two-dimensional which is comprised of two cells differing slightly from each other. Increasing insulation ratio led to reduce the base of right cell while increase the base of left cell. Further increase of insulation ratio change the flow into one-dimensional as shown in Figure ( 6-d ). The reason of the above behaviors could be explained as follows : the increasing in the insulation ratio reduces the heated part. Thus, when the heated part is large there will be enough distance to heat the fluid and rise up at somewhere on the heated 
wall, so the chance of form two-dimensional flow is very likely. Figure ( 7 ) shows the effect of insulation on flow field and temperature distribution at the same Rayleigh number $\left(\mathrm{Ra}_{\mathrm{m}}=\right.$ 250 ) but at inclination angle ( $\gamma=30^{\circ}$ ). It is obvious that the flow consist of one cell (i.e. one dimensional flow ) because the effect of inclination.

( a )
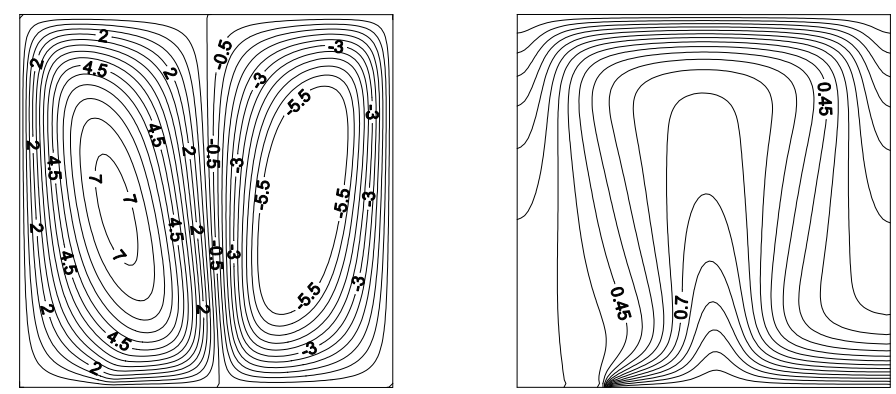

$(\mathrm{b}$
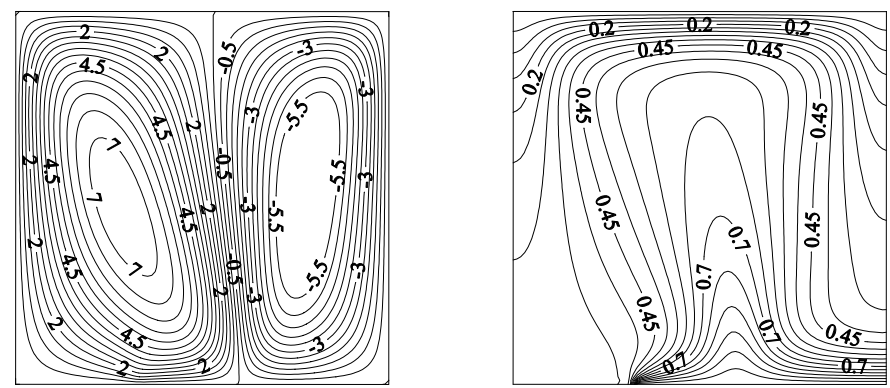

(c)
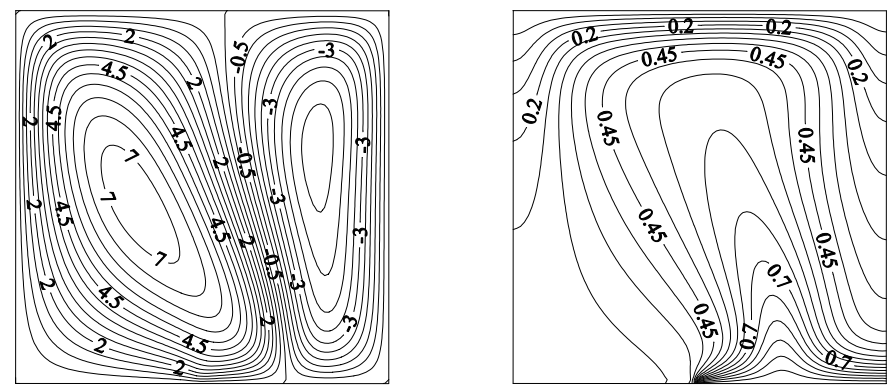

(d)
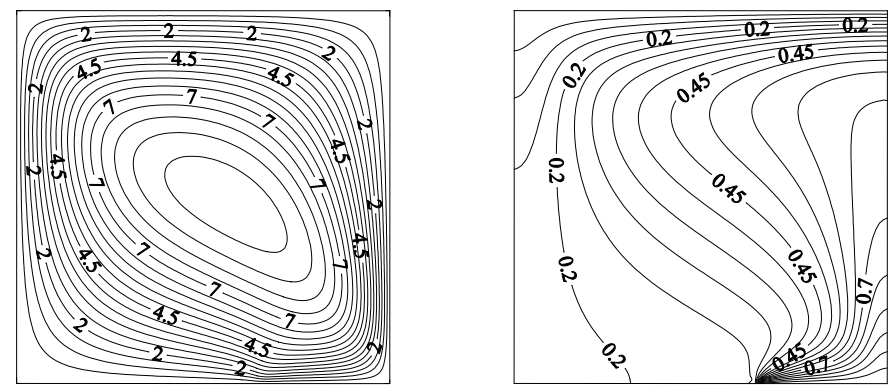

Figure ( 6 ) Effect of insulation ratio on flow field and temperature distribution at Rayleigh number ( 250 ) and inclination angle ( 0 ) for insulation ratio : (a ) $1 / 4$, (b ) $1 / 3$, , c ) $1 / 2$ and (d ) $2 / 3$. 
( a )
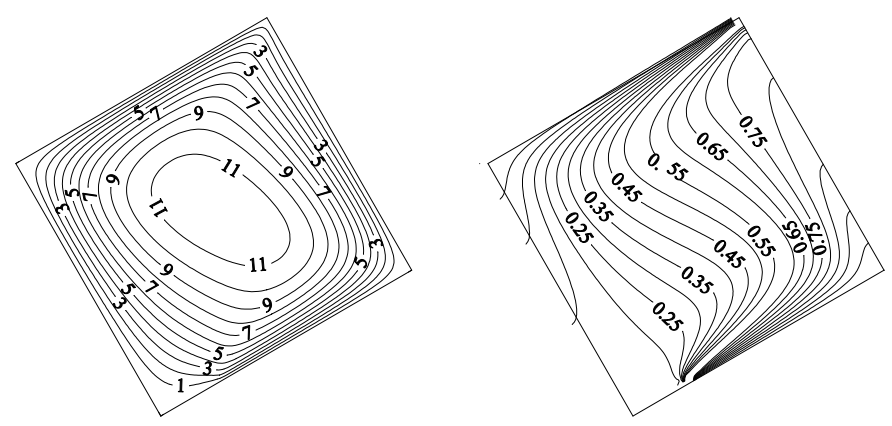

(b)
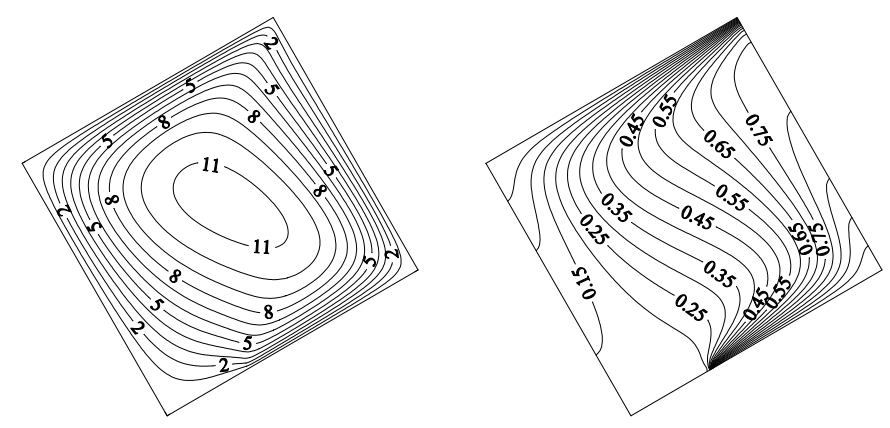

( c )
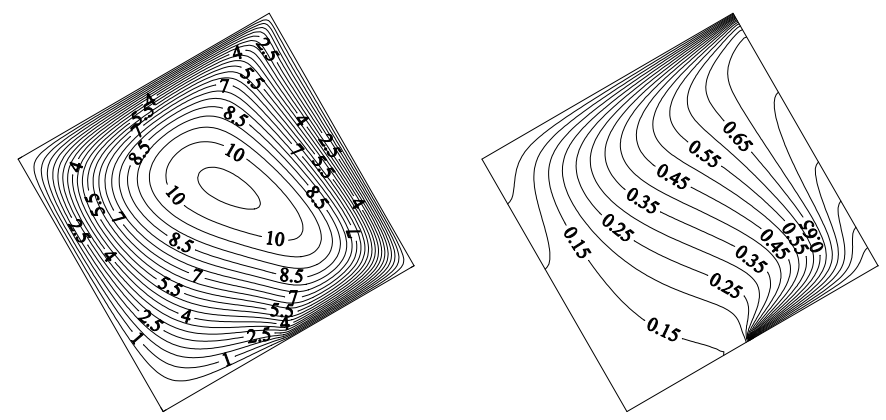

( d )
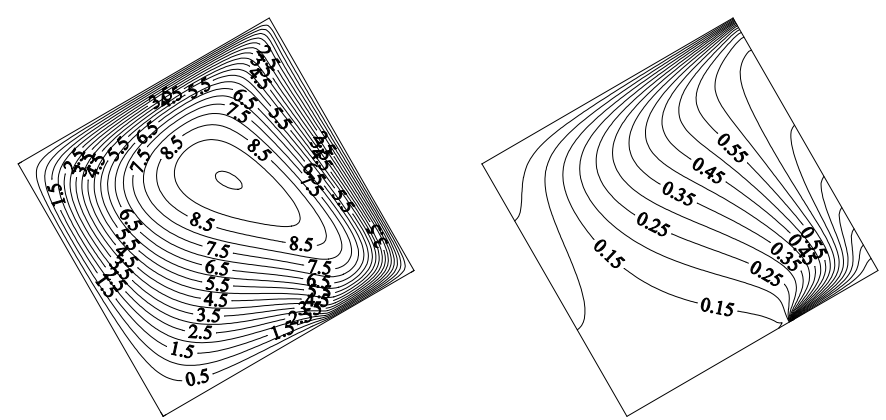

Figure ( 7 ) Effect of insulation ratio on flow field and temperature distribution at Rayleigh number ( 250 ) and inclination angle ( $\left.30^{\circ}\right)$ for insulation ratio : ( a ) $1 / 4$, , b ) $1 / 3$, (c) $1 / 2$ and (d ) $2 / 3$. 
On the other hand, the effect of insulation ratio on Nusselt number is illustrated in Figure ( 8 ). Figure ( 8 -a ) shows the relationship between Nusselt number $(\overline{\mathrm{Nu}})$ and inclination angle $(\gamma)$ for Rayleigh number $\left(\mathrm{Ra}_{\mathrm{m}}=50\right)$. It is noted that Nusselt Number decreases as insulation ratio increase. Furthermore, it is seen that the angle of maximum heat transfer also decreases as insulation ratio increase.

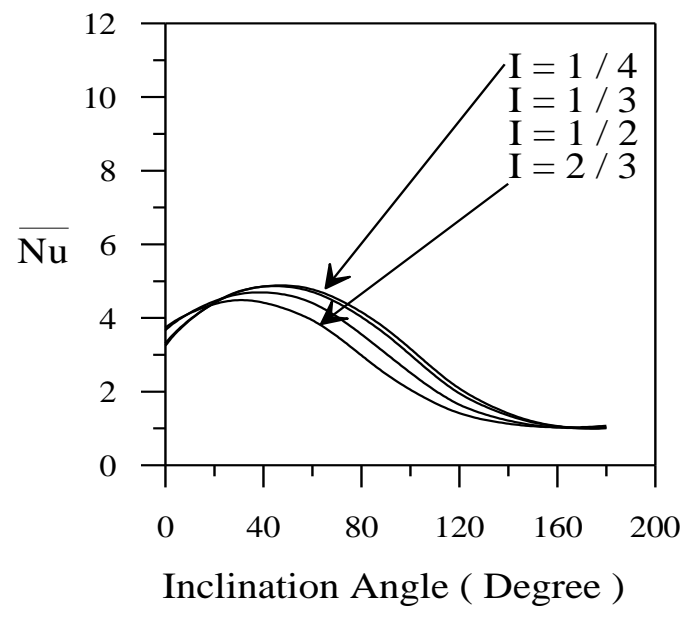

( a )

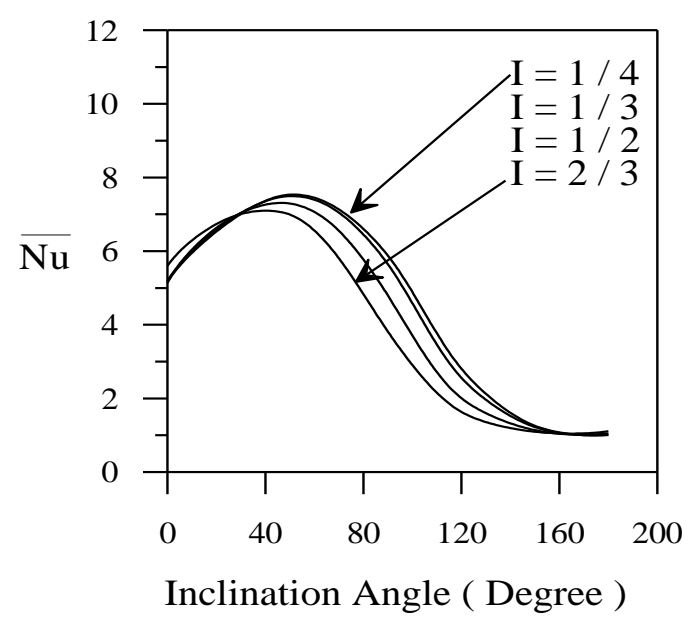

(c)

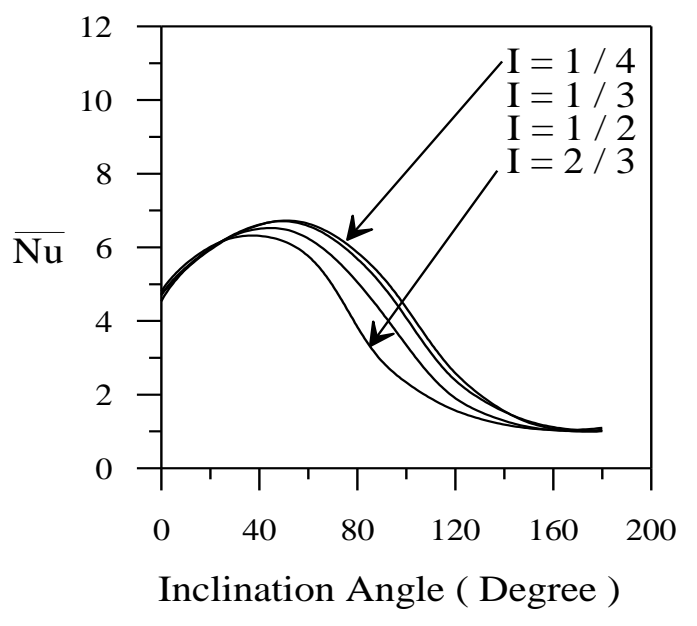

( b )

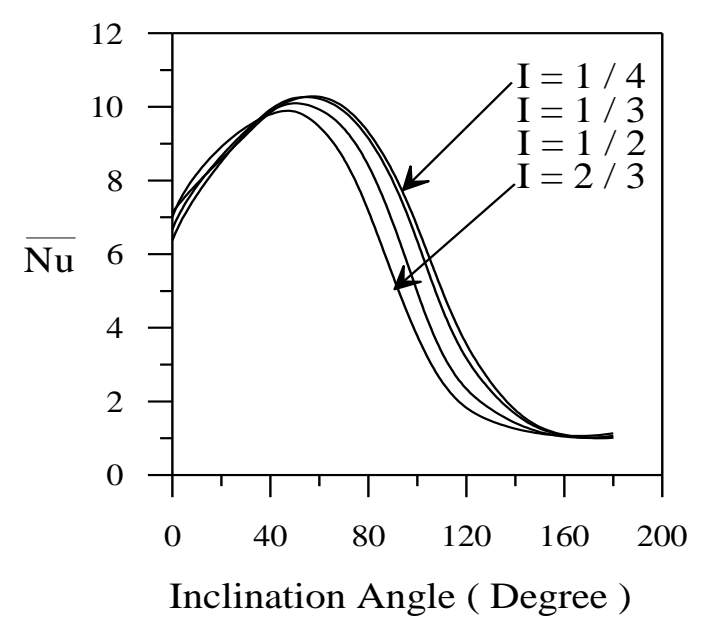

( d )

Figure ( 8 ) Effect of inclination angle on Nusselt number with different values of insulation ratio and Rayleigh number : ( a ) $R a m=50$, ( b ) $R a m=150$, (c) Ram $=300$ and (c ) $\operatorname{Ram}=500$. 


\section{Conclusions}

From aforementioned results, the following conclusions are noticed :

1. The average rate of heat transfer increases as modified Rayleigh number increase for all cases.

2. The average rate of heat transfer increases with increasing inclination angle, reaching maximum value then decreasing until be unity at inclination angle $180^{\circ}$.

3. The average rate of heat transfer decreases with increasing insulation ratio.

4. The angle of maximum heat transfer decreases with increasing insulation ratio.

\section{REFERENCES}

1. Hakan F. Oztop ," Natural Convection in Partially Cooled and Inclined Porous Rectangular Enclosures,” Int. J. Thermal Sciences, 46, pp.149-156, 2007.

2. Lai, F. C., and Kulacki, F. A., " Experimental Study of Free and Mixed Convection in Horizontal Porous Layers Locally Heated from Below," Int. J. Heat Mass Transfer, 34, pp.525-541, 1991.

3. Dawood, A. S.," Natural Convection in a Rectangular Enclosure Filled with Porous Media with Partial Heating from Below," AL-Rafidain Engineering, 4, pp.86-101, 1996.

4. Bourich, M., Hasnaoui, M., and Amahmid, A.," Double-Diffusive Natural Convection in a Porous Enclosure Partially Heated from Below and Differentially Salted," Int. J. Heat and Fluid Flow, 25, pp.1034-1046, 2004.

5. Pakdee, W., and Rattanadecho, P.," Unsteady Effects on Natural Convection Heat Transfer through Porous Media in Cavity due to Top Surface Partial Convection," Applied Thermal Engineering , 26, pp.2316-2326, 2006.

6. Baytas, A. C.," Entropy Generation for Natural Convection in an Inclined Porous Cavity,” Int. J. Heat Mass Transfer, 43, pp.2089-2099, 2000.

7. Bejan, A., Convection Heat Transfer, Wiley-Inter science Publication, Joun Wiley \& Sons, Inc., 1995.

8. Hakan F. Oztop and et. al.," Natural Convection in Right-Angle Porous Trapezoidal Enclosure Partially Cooled from Inclined Wall," Int. com. In Heat and Mass Transfer, 36, pp.6-15, 2009.

9. N.H. Saeid, I. Pop, "Natural Convection from a discrete Heater in a Square Cavity Filled with a Porous Media," J. Porous Media, 8 ,pp. 55-63, 2005.

10. A. Bejan, " on the boundary Layer Regime in a Vertical Enclosure Filled with a Porous Medium," Lett. Heat Mass Transfer,6,pp.93-102,1979.

11. Dawood A. S. and Ismaeel M.E." Numerical Study of Natural Convective Heat Transfer in an Inclined Square Porous Layer" AL-Rafidain Engineering, 16, pp.81-95, 2008. 